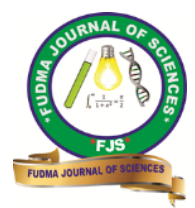

FUDMA Journal of Sciences (FJS)

ISSN online: $2616-1370$

ISSN print: 2645 - 2944

Vol. 4 No. 3, September, 2020, pp $162-169$

DOI: https://doi.org/10.33003/fjs-2020-0403-361

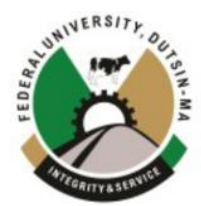

\title{
HOUSEHOLD'S RESPONSES TO THE ROLES OF TREES AS WIND BREAKER IN DUTSE LOCAL GOVERNMENT AREA OF JIGAWA STATE, NIGERIA
}

\author{
*Ilu, K. J., *Salami, K. D., Gidado, A. H., Muhammad, Y. K. and Bello Ahmed \\ Department of Forestry and Wildlife Management, Federal University Dutse, Jigawa State, Nigeria. \\ *Corresponding Author’s Email: foristsalam@yahoo.com, ilukawuwa@gmail.com +2348178584783
}

\begin{abstract}
Wind is a natural process through which air moves in mass from high pressure areas to low pressure areas. There is no doubt when not obstructed can damage several natural features and human-made structures beyond repairs. However, in an open landscape trees provide the most effective protection compared to other biological wind control measures. This study investigated household's responses to the roles of trees as wind breaker in Dutse Local Government Area of Jigawa State, Nigeria. The data were collected with the aid of structured questionnaires coupled with oral interview schedules. A total of five (5) wards namely: Chamo, Dundubus, Limawa, Kaci and Dutse were randomly selected based on the havoc caused by wind in the areas. Fifteen villages were randomly selected from five wards. Thirty (30) respondents were randomly selected from each of the chosen wards; thus, one hundred and fifty (150) respondents make up the sample size for this research while the data were subjected to descriptive statistics analysis. Multistage random sampling was used for this research. The results from this study showed that dominant tree $(67 \%)$, deforestation $(62 \%)$, fuel-wood $(60 \%)$ and tree planting $(60 \%)$ had the highest percentage. In conclusion, Dutse people are greatly depend on the use of fuel-wood for their domestic uses and also aware of mitigating methods. Therefore, enlighten of the people on the effect of deforestation and also alternative sources of biofuel must be provided in order to maintain ecological balance, and reduce high level of deforestation in the study areas.
\end{abstract}

Keywords: Household's perceptions, wind, trees and protection.

\section{NTRODUCTION}

Deforestation results from a mixture of economic, social and political causes that vary from site to site. The primary causes of deforestation in the tropics are logging and its conversion to agricultural production or grazing (Rowe et al., 1992; Salami et al., 2018). The human activities have also been reported as one of the causes of wind erosion. Wind is considered as any air currents or moving mass of air from high pressure areas to low pressure areas. Typically, air under high pressure normally moves towards areas under low pressure. Thus, the greater the pressure difference, the faster the flow of air which creates moving air with considerably strong force (Jetstream, 2008). Winds are commonly classified by their spatial scale, their speed, and the types of forces that cause them, the regions in which they occur, and their effect (Donald, 2005).

In meteorology, winds are often referred to according to their strength, and the direction from which the wind is blowing. A short burst of high-speed wind is termed gusts. Strong winds of intermediate duration (around one minute) are termed squalls. Long-duration winds have various names associated with their average strength, such as breeze, gale, storm, and hurricane (WMA, 2013). Within the tropics, thermal low circulations over terrain and high plateaus can drive monsoon circulations while in coastal areas the sea breeze/land breeze cycle can define local winds; in areas that have variable terrain, mountain and valley breezes can dominate local winds (Musial and Ram, 2010).
When winds become strong, trees and human-made structures are damaged or destroyed. Winds can shape land forms, through a variety of Aeolian processes such as the formation of unfertile soils and erosion. Dust from large deserts can be moved to a great distances from its source region by the prevailing winds; winds that are accelerated by rough topography and associated with dust outbreaks have been assigned regional names in various parts of the world because of their significant effects on those regions (AMS, 2009). Wind also affects the spread of wild fires; can disperse seeds from various plants, enabling the survival of those plant species, and also the flying insect populations (Jetstream, 2008). However, trees provide the most effective protection compared to other biological wind control measures. According to Newton's law of motion, trees by their drag exert a force an wind flow that is compensated by a loss of momentum of the air, and hence, a loss of velocity thus the drag is converted into wind speed reduction commensurate with the tree efficiency (Staple and Lehare, 1999). Indeed, the negative effect of winds in developing countries outweigh its positive impacts on the socio-economic well-being of the people as could be seen in (Figures 1 to 3). The adoption of preventive measure to such kind of devastation relied upon the awareness of individuals on the actual remedy to adopt for a stoppage to such frustrating situation. The present study aimed to determine household's responses the roles of trees as wind breaker in Dutse Local Government Area of Jigawa State, Nigeria for better awareness and enlightenment against deforestation and provision of alternative provision of fossil fuel. 


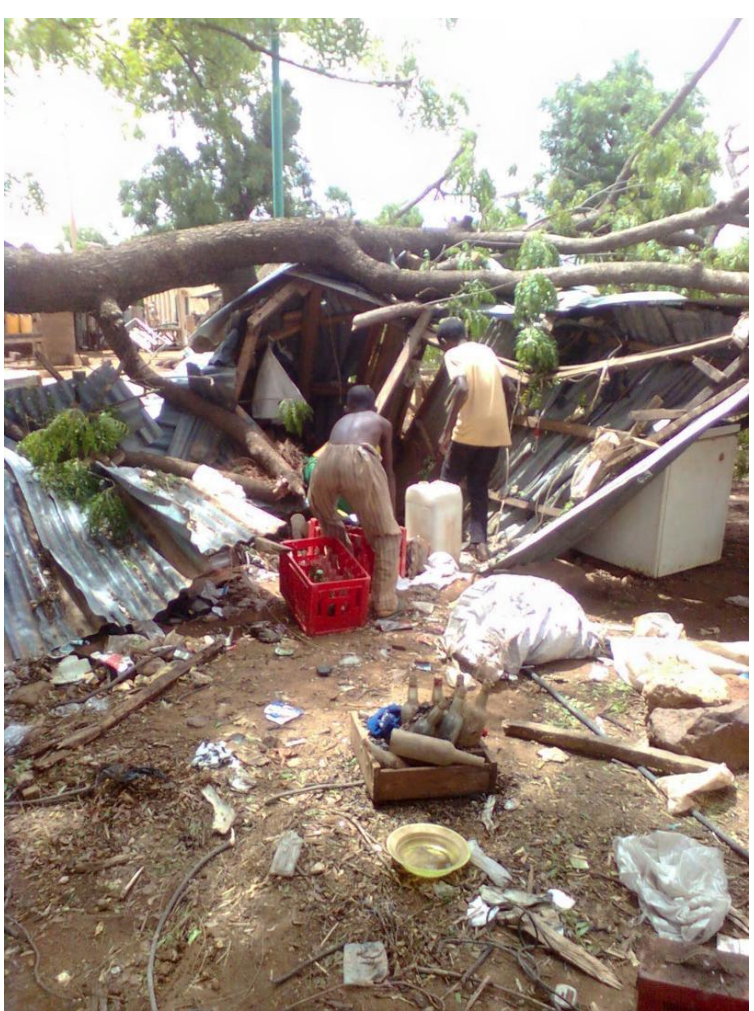

Plate 1: Wind action on settlement in June, 2019 at study area Source: Field Survey, 2019.

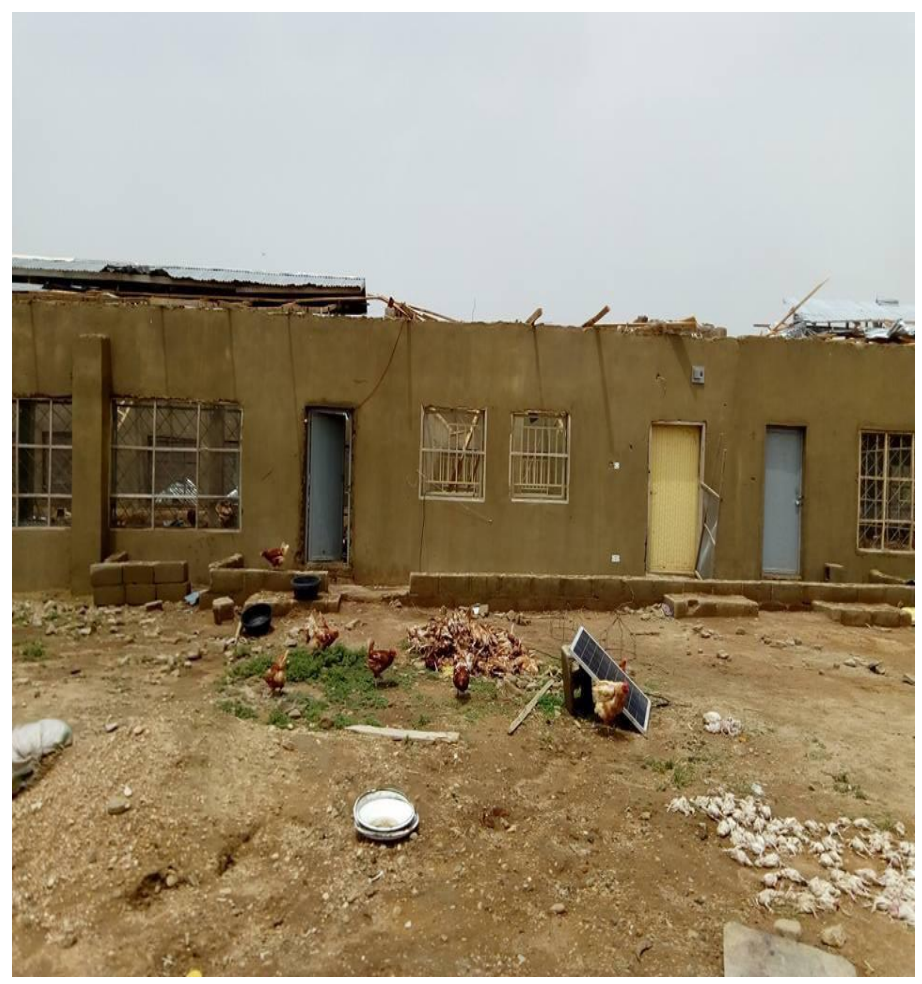

Plate 2: Poultry house damaged by wind at study site Source: Field Survey, 2019. 


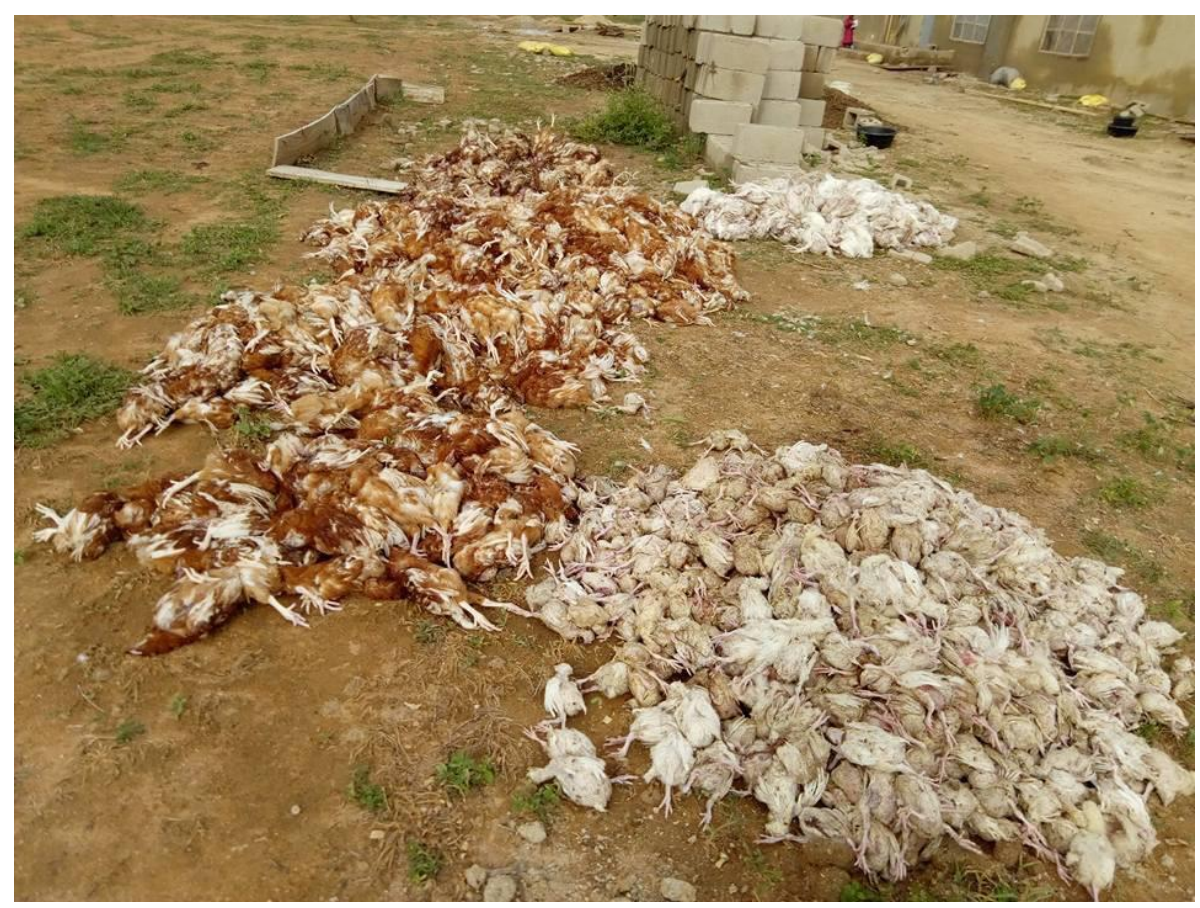

Plate 3: Casualties encountered at poultry farm due to wind damage Source: Field Survey, 2019.

\section{METHODOLOGY}

\section{Study area}

The study was carried out in Dutse Local Government Area (LGA), Jigawa State, Nigeria capital which is geographically located at latitude $11^{0} 42^{\prime \prime} \mathrm{N}$ and longitude $9^{0} 20^{\prime \prime} \mathrm{E}$ at an elevation of $435 \mathrm{~m}$ above the sea level. The rainy season lasts from May to September with an average annual rainfall of between $600 \mathrm{~mm}$ to $1000 \mathrm{~mm}$ and high temperatures are normally recorded between the months of April and September (JSSYB, 2009). Jibo et al. (2018), revealed that it covered by Sudan savanna, also characterized by hot wet summer and cool dry winter with average raining season of 3-5 months (644 $\mathrm{mm})$ as it reported by Salami and Lawal, (2018). The inhabitants are predominantly farmers engage in farming and rearing of livestock (Richard et al., 1997). Dutse is predominantly occupied by Hausa and Fulani with an estimated population of 153,000 (NBS, 2006). The topography is characterized by high land area which is almost $750 \mathrm{~m}$. Soil tends to be fertile ranging from sandy-loam (Salami and Lawal, 2019).

\section{Data collection and experimental design}

A total of thirty (30) respondents were randomly selected from each of the chosen wards; thus, a total of one hundred and fifty (150) respondents make up the sample size for this research, using Multi-stage random sampling technique. The data were collected with the aid of structured questionnaires coupled with oral interview schedules that captured responses on the availability of trees in the area, causes of wind damage, involvement in tree planting activities, the status of the wind destruction and preventive measure instituted. A total of five (5) wards were purposively selected based on the havoc caused by the areas, three villages were selected from each ward as follow: Chamo (Sukullifi, Damargel, Larabawa), Limawa (Galamawa, Garu, Yina) Dubudus (Zanbon buji, Buji, Kacha), Kachi (Fagoji, Zai, Gidadubu) and Dutse (Fanisau, Marabusawa and Danmasara). Ten (10) respondents were selected from each village.

\section{Data analysis}

The data were analyzed using Statistical Package for Social Sciences (SPSS). Descriptive statistics such as: pie chart.

\section{RESULTS}

Demographic characteristics of the respondents

Data on demographic characteristics of the respondents are presented in Table 1. The table revealed that the age bracket of 31-40 had the highest frequency of respondents while a better percentage of respondents had least secondary school education (36.67\%). Gender distribution of respondents indicates that $66.67 \%$ of the respondents were male while $33.33 \%$ were female. Distribution of respondents' marital status showed that $1.33 \%$ were widow, while $56 \%$ were married. The prominent religious faith in the study area was Muslims. 
Table 1: Demographic characteristic of the respondents

\begin{tabular}{llll}
\hline Variables & Characteristics & Frequency & Percentage (\%) \\
\hline Gender & Male & 100 & 66.67 \\
& Female & 50 & 33.33 \\
\hline Total & $21-30$ & $\mathbf{1 5 0}$ & $\mathbf{1 0 0}$ \\
\hline Age & $31-40$ & 103 & 68.67 \\
& $41-50$ & 34 & 22.67 \\
& $51-60$ & 09 & 06 \\
\hline & Total & 04 & 2.67 \\
\hline Marital status & Married & $\mathbf{1 5 0}$ & $\mathbf{1 0 0}$ \\
& Single & 60 & 40 \\
& Divorced & 84 & 56 \\
& Widow & 04 & 2.67 \\
& Total & 02 & 1.33 \\
\hline Educational qualification & Primary & $\mathbf{1 5 0}$ & $\mathbf{1 0 0}$ \\
& Secondary & 31 & 41.33 \\
& Tertiary & 55 & 36.67 \\
\hline & Total & 64 & 42.67 \\
\hline Occupation & Student & $\mathbf{1 5 0}$ & 49.33 \\
& Farming & 74 & 12 \\
& Business/Civil servant & 18 & 27.33 \\
& House wife & 41 & 11.33 \\
\hline
\end{tabular}

Source: Field survey, 2019

Dominant trees species in the study area

It was revealed that $(67 \%)$ of the respondents established that A. indica was the dominant tree species in the study area, whereas Adansonia digitata and Parkia biglobosa account for only $5 \%$ of the tree species.

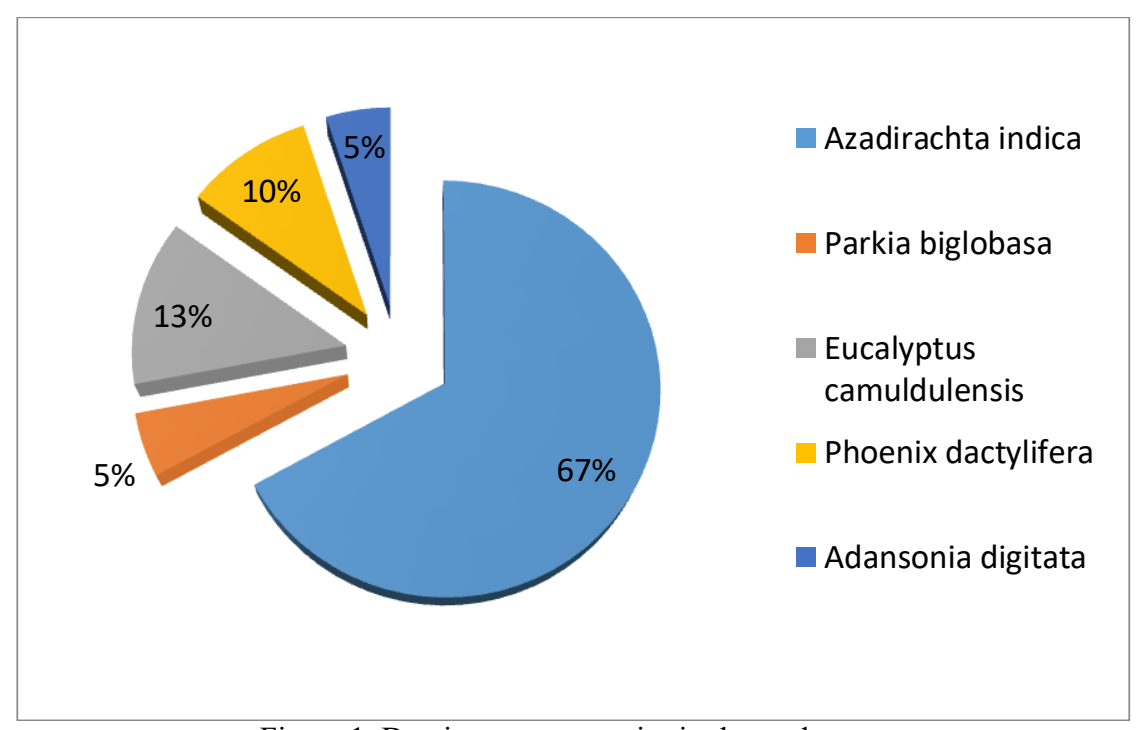

Figure 1: Dominant trees species in the study area Source: Field survey, 2019

Major causes of tree depletion in the study area

Deforestation (62\%) was found to be the major cause of tree diminution followed by overgrazing $(21 \%)$ while other means ( $1 \%)$ of tree attenuation were found to be the least in the study area (Figure 2). 


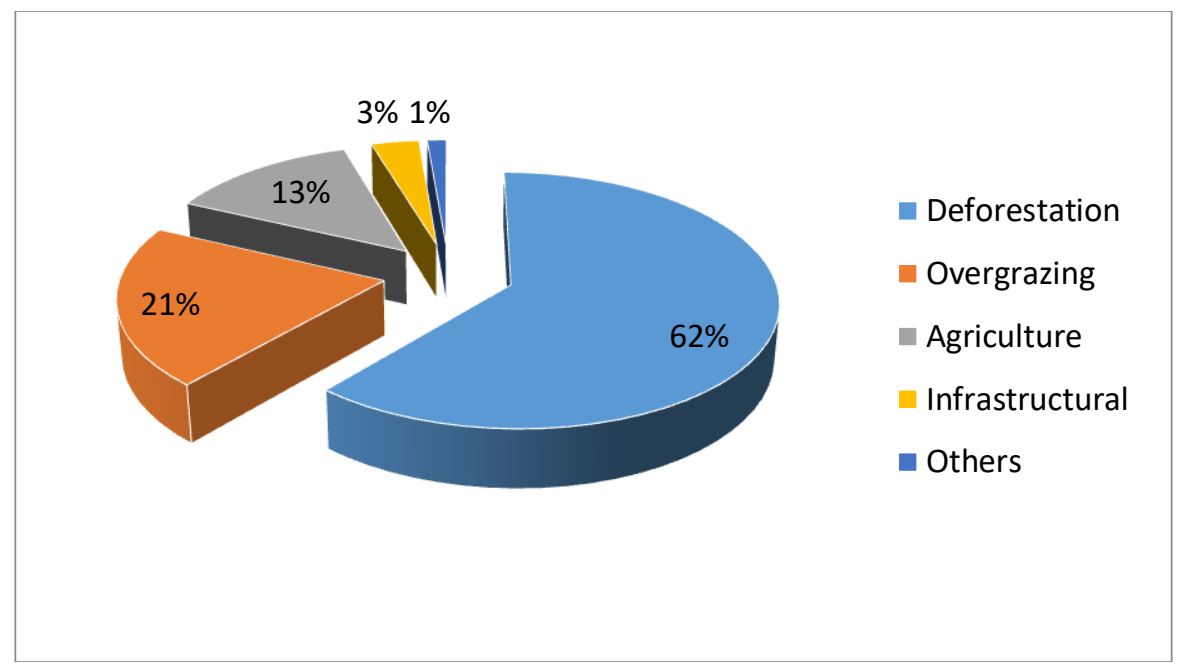

Figure 2: Major causes of tree depletion in the study area Source: Field survey, 2019

Frequency occurrence of wind damage in the study area

It could be seen that $(50 \%)$ of the respondents agreed that wind damage occurred very frequently, meanwhile, (30\%) affirmed that the frequency of occurrence cannot be predicted, $(2 \%)$ of the respondents had no idea (Figure 3 ).

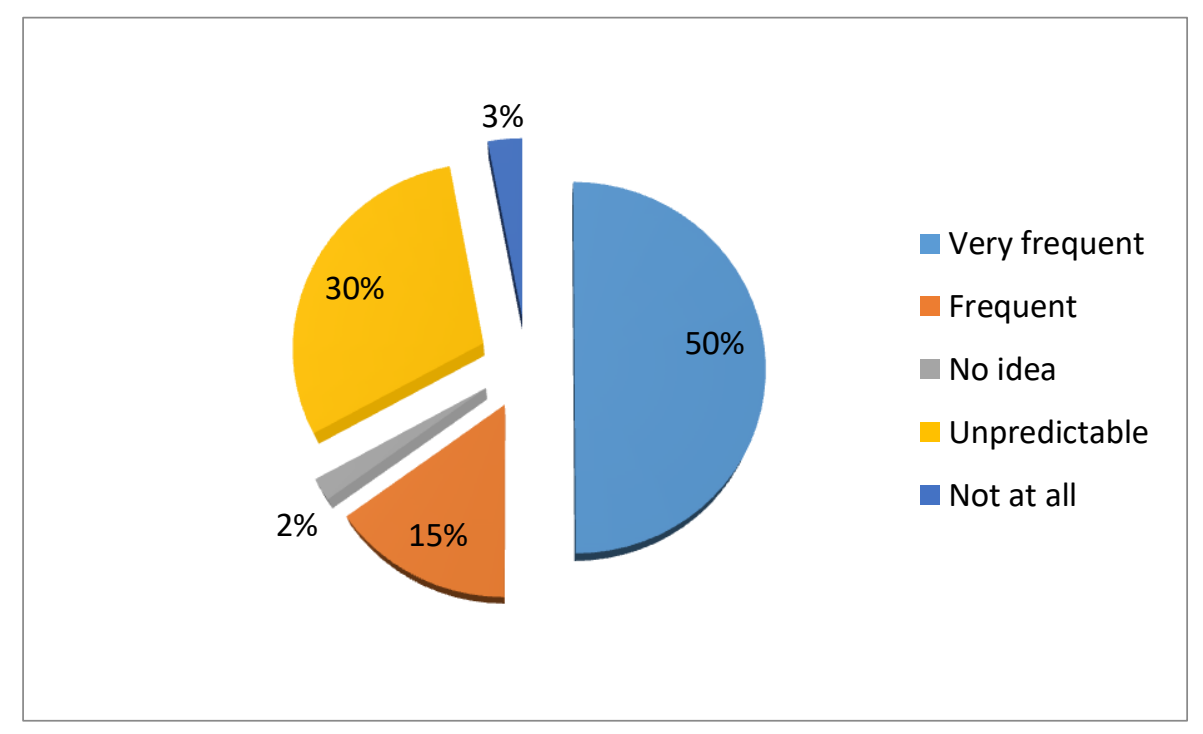

Figure 3: Frequency occurrence of wind damage in the study area Source: Field survey, 2019

Major sources of fuel in the study area

Sixty percentage (60\%) fuel wood was found to be the major sources of energy supply followed by $20 \%$ charcoal. Mean while, electricity (2\%) was the least source of energy for daily heating activities (Figure 4). 


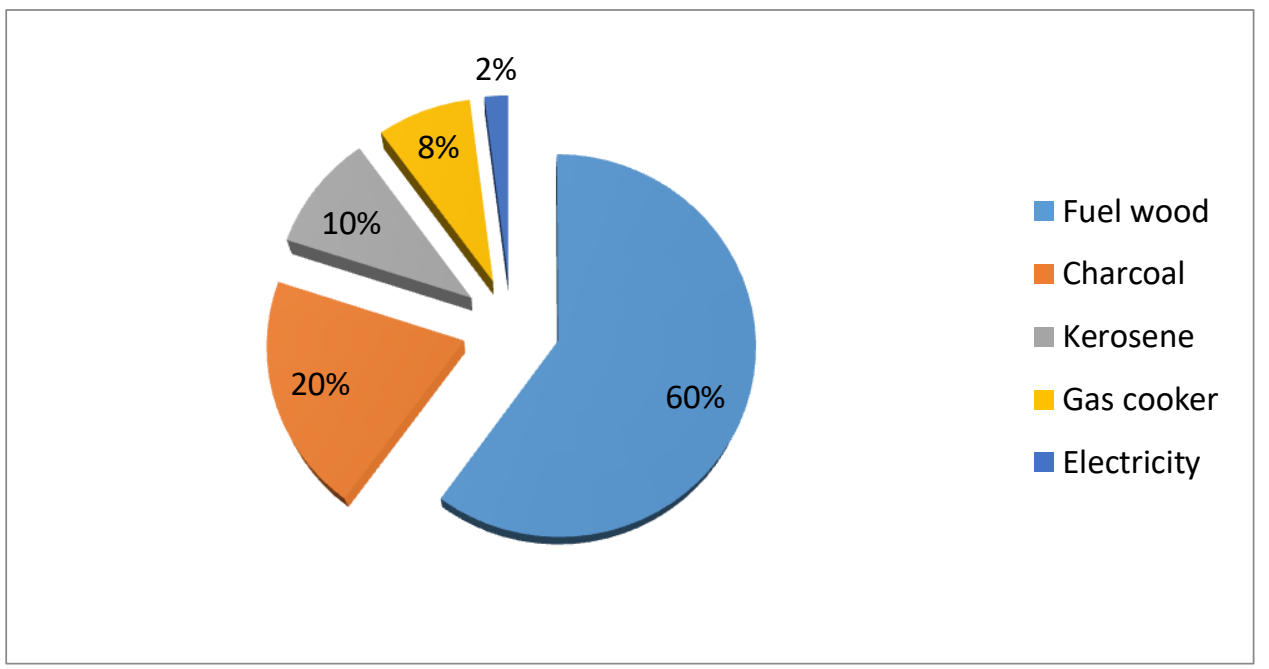

Figure 4: Major sources of fuel in the study area Source: Field survey, 2019

Involvement in tree planting activities in the study area $(53 \%)$ of the respondents indicated their non-involvement in tree planting activities, while, $(10 \%)$ indicated their involvement in tree planting activities (Figure 5)

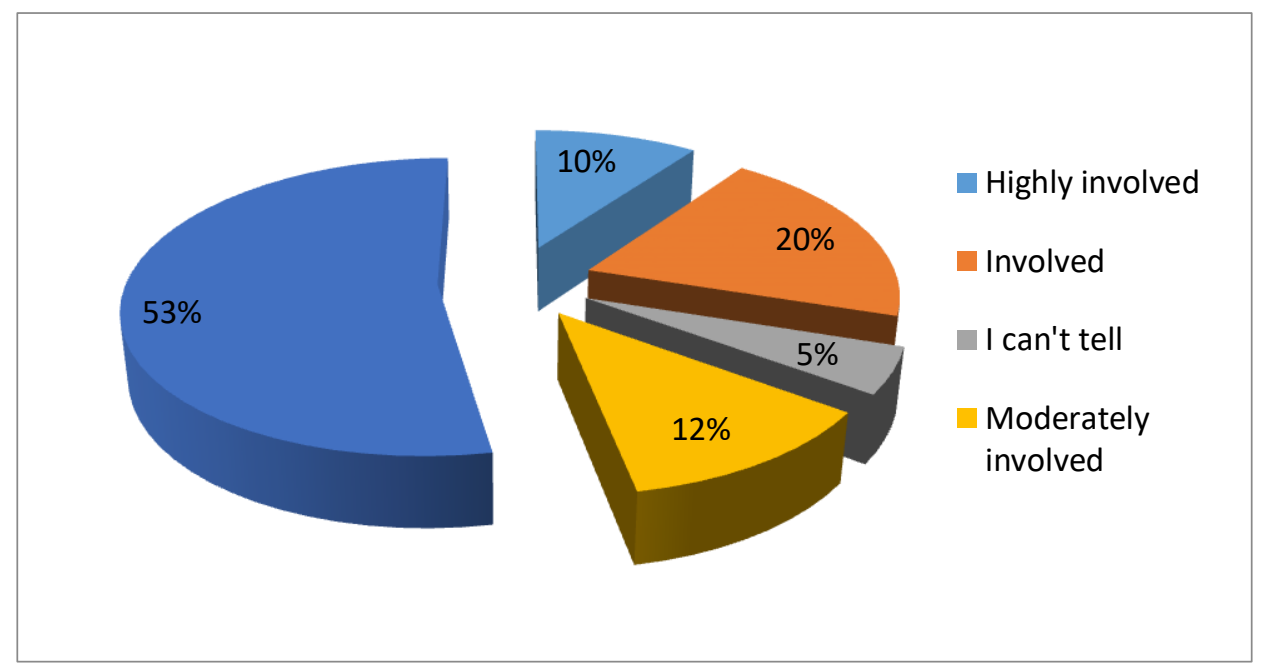

Figure 5: Involvement in tree planting activities in the study area

Source: Field survey, 2019

\section{Ways of mitigating wind damages}

Sixty percent $(60 \%)$ of the respondents recommended the tree planting activities amongst the possible solutions mitigate wind damages, while, only ( $1 \%$ ) had no idea of the way out to wind damages (Figure 6) 


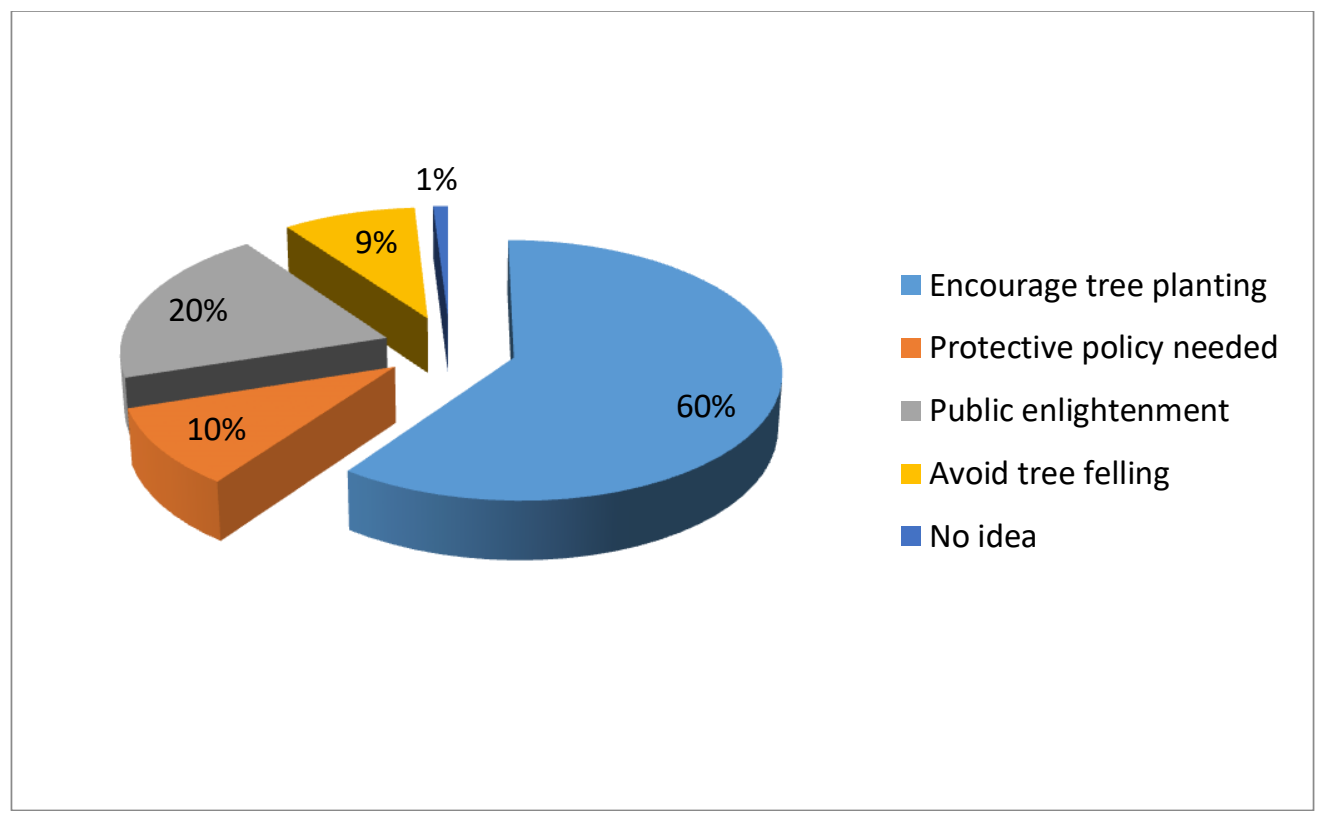

Figure 6: Ways of mitigating wind damages in the study area

Source: Field survey, 2019

\section{DISCUSSION}

The dominant tree species in the study areas are exotic tree species which are A. indica tree and P. biglobosa. This implies that the indigenous tree species have been exploited and used for domestic fuel and other services. Salami et al. (2019), agreed with the finding as they observed that the family of Melieacea had the highest number of frequency of occurrence: A. indica (10) and K. senegalensis (8) while Fabaceae had more prevalent species (14) in the study area. It was also noted that deforestation was the major causes of tree depletion in the area investigated. Nasa Earth Observatory, (2017) concurs with observation that direct causes of deforestation are agricultural expansion, wood extraction (logging or wood harvest for domestic fuel or charcoal), and infrastructure expansion such as road and building construction, and urbanization. Most often, multiple processes work simultaneously or sequentially to cause deforestation. Indeed Faleyimu and Oluwalana (2008) stated that in many parts of the world, trees are being cut down faster than they are replanted. Popoola et al. (2009), observed that mankind exploit many species for economic benefits which results in serious reduction in biodiversity and many species becoming extinct more rapidly than researchers can study them. However, despite the fact that, these native trees have slow growth rate and long gestation period, they are generally noted as good sources of medicinal products used in the treatments of certain ailments that are difficult to cure by using the conventional drugs. Thus, Popoola et al. (2009), purported that strong wind occur in areas with little or no vegetation, often in areas where there is insufficient rainfall to support vegetation. The findings have also revealed that, dwellers of the study areas had suffered from various environmental challenges in form of destruction of dwelling sites, annihilation of chickens and a host of other calamities (Plates 1, 2 and 3). Derek (2006) noted once wind exceed $135 \mathrm{knots}(250 \mathrm{~km} / \mathrm{h})$, structures can be destroyed. The level of dependence on fuel wood is high. The result from this study agreed with Orifah et al. (2018), who reported that rural people in Dutse depend largely on wood and charcoal as a dominant biomass energy sources.

The respondents were of the opinion that wind damage can be curtailed through tree planting exercise even though their participation in reforesting the environment was insignificant. This is supported by (www.derm.qld.gov.au) that most effective method of controlling erosion by both wind and water is to maintain adequate levels of cover on the soil surface. Forest forms a major part of resources through which status of any given community could be assessed as it makes the atmosphere conducive for habitation, if properly managed and renewed, it could provide employment to a great number of people, protect structures and host of other services that might not be quantified. FAO (2016) states that forest could help in some important ways to reduce food scarcity, alleviate poverty, improve the sustainability of agricultural production and the environment in which rural people live all over the World.

\section{CONCLUSION}

The respondents were quite aware of the benefits of trees in checking wind damage, but they were reluctant in seizing the advantage of embarking on tree planting. Larger percentage of the Dutse people are highly depend on fuel wood for their livelihood; more so, effort should be made in converting this energy source into useful facilities for the enhancement of human and animal life.

Ministry of Environment in the state, Non-Governmental Organization, village heads, educational centers should involve in public awareness, enlighten the individuals, families and groups on the issue of deforestation and advantages of tree planting.

\section{REFERENCES}

AMS, (2009). "Chandra Finds Fastest Winds from Stellar Black Hole". NASA. Retrieved September 27, 2012. 
Department of Environmental and Resources Management www.derm.qld.gov.au retrieved $21^{\text {st }} /$ July/2020

Derek, B. (2006). "How to Minimize Wind Damage in the South Florida Garden". University of Florida. Retrieved 200905-13.FAO (2016): Global Forest resource assessment. Proceeding of the Forestry Association of Nigeria, 2006(1):140-149.

Donald, K. Y. (2005). "World Book at NASA: Comets". National Aeronautics and Space Administration. Archived from the original on 2015-03-21. Retrieved 2009-06-20.

Faleyimu, O. I. and Oluwalana, S. A. (2008): Efficacy of Medicinal Forest plant seed in Ogun State Nigeria. Journal of tree club, 26(1): 63-67

FAO, (2016). The state of Food and Agriculture: Climate change, Agriculture and food security ISBN 978-92-5-1093740 retrieved $18^{\text {th }}$ July, 2020.

Jetstream, J. J. (2008). "Origin of Wind." .National Weather Service Southern Region Headquarters. Retrieved 2009-02-16.

Jibo, A.U., Salami, K.D. and Inuha, I.M. (2018). Effects of Organic manure on growth Performance of Azadirachta indica (A.Juss) seedlings during early growth in the Nursery. FUDMA Journal of Sciences 2 (4):99-104

Jigawa State Agricultural Development Project. (2009): Progress Report on the Afforestation Programme. Jigawa State of Nigeria, Jigawa State Statistical Year Book 2008. Pp 12-20

Musial, W. and Ram, B. (2010). "Large-Scale Offshore Wind Power in the United States," U.S. National Renewable Energy Laboratory, NREL/TP-500-40745, September 2010

Nasa Earth Observatory: (2007) Causes of Deforestation

National Bureau of Statistic (2006): Core indicators questionnaire survey reports on Jigawa. Abuja, Nigeria.

Orifah, M. O., Ijeoma, M. C., Ehien, 1., Nasiru, A. E. . and Fadairo, O. S. (2018) Awareness of the health implications of use of biomass energy sources among women in rural households of Jigawa State, Nigeria. Agricultura Tropica Et Subtropica, 51(2):93-101.

Popoola, L. A., Adejumo B. O. and Solomon, A.A. (2009): Review of Millenium Development Goal (MDG) In Relation to Forest in Nigeria. Proceeding of Forestry Association of Nigeria. 2009. 1: 114-120

Richards, J. (1997). Plant Breeding Systems. Taylor and Francis. p. 88. ISBN 978-0-412-57450-4. Retrieved 2009-0619.

Rowe, W. B., Del-Genio, A.D. and Eichler, T. (1992). "Cloudtracked winds from Pioneer Venus OCPP images". Journal of the Atmospheric Sciences. 47 (17): 2053-2084. Bib code: 1990JAtS.47.2053R. Doi: 10.1175/1520-0469(1990)047<2053: CTWFVO>2.0.CO; 2.

Salami, K. D. and Lawal, A. A (2018). Tree Species Diversity and Composition in the Orchard of Federal University Dutse, Jigawa. Journal of Forestry Research and Management. 15(2).112-122; ISSN 0189-8418.

Salami, K. D., Ilu, K. J., Odewale, M. A., Gidado, A. H. and. Umukoro, S. U. (2019). Canopy Structure of Secondary Forest in The Federal University Dutse, Jigawa State: Composition and Importance of Woody Species FUW Trends in Science \& Technology Journal, 4 No. 2 pp. 611 - 616 www.ftstjournal.com e-ISSN: 24085162; p-ISSN: 20485170

Salami, K. D., Nurudeen, T. A. and Ringim, A. S. (2018). Status of Forest Ecosystem and It's Conservation in Nigeria. World Environmental Conservation Conference held Theodore Idibiye Francis Auditorium, The Federal University of Technology, Akure, Ondo State, Nigeria Pp 93-99

Staple, W. Z. and Lehare, J. J. (1999). Influence of field shelterbelt on wind velocity, soil Moisture and crop yield. Journal of Agricultural Science 35: 440-453.

World Meteorological Association: World Record Wind Gust: 408 km/h". "Info note No. 58 2013-01-20. 